\title{
A Critical Reflection of Collaborative Inquiry: To what extent is collaborative learning beneficial in my classroom? Bianca Lavorata
}

\section{Introduction}

Twenty years ago, I was a Grade 6 student in a Grade 6/7 classroom. I remember learning material through direct teacher instruction. The structure was quite clear-cut; the teacher transmitted information and the students listened and absorbed the material. Tests were distributed, graded, and then new content would be introduced. Students were seated in rows, sometimes according to alphabetical order, which inhibited peer intermingling and interaction. This type of traditional teaching still exists in many classrooms despite educational advances that highlight the importance of collaborative student-centred learning rather than a teacher-centred classroom. I strongly maintain that "a major value of collaboration, the reason why it is so praised in our rhetoric, is that we can do more and better work collaboratively than we can alone" (Johnston-Parsons, M., 2010, p. 289). Student centred learning may be referred to as learning that "has student responsibility and activity at its heart, in contrast to the stronger emphasis on teacher-control and the coverage of academic content" found in much traditional teaching classrooms (Cannon, R., Ingleton, C., Kiley, M., \& Rogers, T., 2000, pg.3). I further extend this definition and place emphasis on student centred learning as a classroom in which students play an active role in their learning, as oppose to a passive role in a teacher-centered learning environment.

When I was a student in grade 6 , collaborative peer interactions were not encouraged. Group work was kept to a minimum and in some cases nonexistent. Independent thinking and collaborative work did not seem to have a substantial part in this structure. How well students performed on examinations was dependent on how well they could regurgitate information on paper and how well one could memorize important facts from multiple worksheets, teacher lectures, or the textbooks students were required to read. Today, as a practicing grade $6 / 7$ teacher, I am able to reflect back to when I was a student, and implement changes in my own classroom that I find 
beneficial to fostering a more collaborative and inclusive learning environment. This paper offers a personal critical reflection of collaborative learning practices based on my teaching experiences. The information presented is not intended to be generalized across all classrooms and learning environments, as it may not pertain to other teaching or nonteaching professionals.

It is no surprise that learning and student needs have shifted greatly since I was a grade 6 student. We now live in an increasingly diverse, interconnected and complex world. Traditionally, teacher-centered methods of instruction focused on rote learning, which is centred on memorization and learning by repetition. When I was a student, I recall students working in isolation and generally not having a voice in the classroom. Working collaboratively in pairs or in small groups was not given much importance. However, I feel that working with others is a key skill that is needed in this inter-connected world. In this paper, I explore the extent in which collaborative learning is beneficial in my grade $6 / 7$ classroom by making reference to personal teaching experiences. I maintain that the knowledge, attitudes, and skills associated with and learned through collaborative learning best prepare students to work and live in an increasingly diverse and interconnected world. How can educators today help meet the needs of learners in this inter-connected world?

Knowledge is not solely based on rote-memorization, but is actively constructed in a way that fosters meaningful learning experiences. Learning should not be textbook-driven, rather textbooks are just one of many resources to help stimulate student thinking. Educators today need to recognize this shift and find ways to help students acquire the necessary skills to be reflective, self-regulated lifelong learners and move away from just accepting everything merely transmitted to them.

Although I was an intermediate student twenty years ago, the traditional classroom setting of which I was a part of still exists in the school system today. I believe this traditional style of teaching does not entirely foster collaborative interactions, as teachers simply transmit information for students to absorb. I see traditional classroom teaching as an impediment to fostering a collaborative classroom community. To what extent is collaborative learning beneficial in my grade 6/7 classroom? First, I will 
begin by presenting a definition of collaborative learning. I will then explore the benefits of collaborative learning in my classroom. In addition, the challenges to collaborative learning that I have observed will be addressed. Finally, I will conclude by discussing ways in which educators can build a community of collaborative inquiry to help foster the potential of collaborative learning.

\section{What is collaborative learning?}

What is collaborative learning exactly? The definition of 'collaborative learning' varies from one scholar to another, from stating it is interchangeable with cooperative learning to describing it as a completely separate notion involving higher-level thinking (Hennessy, 2006).

According to educational theorist, John Dewey, "education is not an affair of 'telling' and being told, but an active and constructive process"(Dewey, 1930, pg. 46). I appreciate and I am in agreement with Dewey's perspective of education, as I believe it sheds light on my outlook of the process of collaborative learning; it is an active process, where a person thinks actively about a certain query, rather than just passively receiving information from someone else. Case extends this thought and suggests that "students who receive information in a passive or transmissive manner are far less likely to understand what they have heard or read about than are students who have critically scrutinized, interpreted, applied or tested this information" (Case, 2005, p. 2). I agree with Case's assertion, as I have found that student understanding of material is increased when they have had the opportunity to collaborate with one another and be active in their learning, as opposed to when they have not had the opportunity to work with the material in this way.

I define collaborative learning as a learning tool and social process in which individuals work together in groups of two or more, jointly constructing meaning, searching for solutions and understandings, or creating a product in order to arrive at a common goal. Accordingly, this will lead to collaborative inquiry. Learners are responsible for their learning and respect the contributions of their group members. All voices are equally important and add to the dynamic nature of a collaborative classroom. This 
mutual exploration and feedback from others often leads to a deeper understanding of a given query (Golub, 1998). I believe it is important for students to work actively in purposeful ways, in which learning is meaningful to them, in order for students to learn new information, skills or ideas that are not merely through direct teacher lecturing.

Because I argue that collaborative learning is a social process, a teacher's role is that of a facilitator, in which the acquisition of knowledge comes predominantly through shared group discussion and negotiation. In other words, collaborative learning exhibits a shift away from the teachercentred traditional classroom, in which students are not active participants, and information is solely being transmitted from the teacher to the student. Thus, by contrast, learning is student-centered, where students are autonomous learners and decision makers while the teacher is the facilitator, and students work together and construct knowledge by sharing and exchanging ideas and skills in order to reach a common goal. Of course, the teacher is also an active member of the collaborative process.

\section{What are the benefits to collaborative learning?}

Based on my teaching experiences and observations, collaborative learning opportunities possess several benefits. I will categorize these benefits as social and psychological. Social benefits include encouraging and building diversity, embracing a shared knowledge between students and teachers, and inviting students to share experiences and view situations from others' perspectives. Additionally, collaborative learning develops social skills and fosters an inclusive classroom environment, which I have found engages and empowers learners by actively involving students in the learning process. Finally, psychological benefits include building selfesteem, reducing student anxiety and having an overall positive attitude towards peers and teachers. Of the various benefits, I will focus on the social aspect of collaborative learning in the classroom.

One benefit that I have seen is the changing relationships between students and teachers. I find that collaborative classrooms encompass shared knowledge. Imagine a lesson on something that few teachers and students have much knowledge about. When students who do have authentic 
experiences are provided with opportunities to share them, the entire learning community in the classroom is enriched. For instance, on a lesson on global issues, I had a student who visited her father's homeland, India, and her personal experience and insight of the region brought forth such a genuine and fascinating personal narrative that would be unavailable by other means. This shared knowledge not only enriched the subject area, but it also deepened the learning of others. In addition, when students notice that their knowledge and experiences are valued and appreciated, I have noticed that they become empowered and engaged. Enabling students to become empowered is important in education today. Sullivan (2002) maintains that empowered students are more likely to satisfy their social needs and achievement goal and fulfil their needs to feel valued and have a sense of purpose. This works hand in hand with student engagement, as students who are able to coordinate social goals are more likely to be engaged in their learning and achieve successful outcomes at school (Sullivan, 2002).

Additionally, in my classroom, I make an effort to co-construct curricular activities with my students in various ways and I have noticed this makes a positive impact in my collaborative classroom community. This is important because students feel respected and valued; their ideas are welcomed and encouraged and in the end, I find they are able to produce better work. In contrast, a traditional classroom teacher is principally responsible for developing all learning tasks, assessing what is learned and setting goals. Collaborative classrooms differ, as they encourage students to co-establish goals provided the learning outcomes are met, give students options for assignments or activities that are of personal interest, and invite students to assess their learning in different ways, such as peer and selfassessment. Altogether collaborative classrooms greatly encourage students to bring their knowledge and thinking to the forefront in ways that make sense to them. Imagine, for example, that students have just finished reading about world hunger and poverty and need to prepare a piece of work on the topic. In a traditional teacher-run classroom, the teacher might ask the class to write a 5-paragraph essay on the matter derived from a textbook, while a collaborative classroom may invite students to generate ideas as to how they would like to present the information they have learned with the connections they have made based on relevant criteria. The advantage of this is twofold. 
First, students have a voice in the decision-making process and, second, students are given opportunities to explore ideas of personal interest. I have seen higher levels of engagement and empowerment when students are provided with choices rather than strictly being told what to do. For instance, during my afternoon writing blocks, I find that when students are given a choice of topics, they are more engaged and involved in the writing activity. Accordingly, there is a sense of purpose and value. However, in a traditional classroom, a topic may simply be chosen by the teacher, which may inhibit students to explore a topic of interest and can lead to disengagement.

Another benefit that I see in my classroom during collaborative learning opportunities is my role as facilitator. As a facilitator, I monitor student progress, provide helpful resources and encourage student problemsolving, which is an important goal in education today. I feel it is important that we see each other as a community of individuals working together to achieve a common goal. As responsibility and knowledge are shared between my students and myself, I find that my role as facilitator helps students connect ideas or new information with their experiences. When students raise questions and discover the answers for themselves, they get involved in their own learning and ultimately construct their own meaning from competing perspectives that stem from collaborative learning experiences.

According to Vygotsky (1978), when students are asked to work in collaborative situations, they are capable of performing at higher intellectual levels, than when they are asked to work in isolation. Group diversity in terms of knowledge and experience contributes positively to the learning process. Bruner (1985) maintains that collaborative learning methods improve problem-solving strategies, as students are confronted with diverse interpretations of a given situation. I am in agreement with Vygotsky and Bruner and have found that when students are given opportunities to work collaboratively, it really allows students to learn with and from each other. For instance, during math blocks, I find that students are keen to work collaboratively on math problems, such as learning from each other the multiple ways one can reach the same solution. Students are able to integrate each other's viewpoints and scaffold each other. I have found that the experiences, backgrounds and perspectives of all students play an important 
role for enriching the learning in my classroom. I believe that when students learn about others' perspectives, it really opens their minds and helps students recognize others' viewpoints and/or preconceived biases of the topic before reaching informed judgment on a given matter. For instance, in a debate on animal rights in my classroom, students not only shared and developed their own perspectives, but they also deepened their understanding on the topic by listening to others who held decidedly different views. As a result, the multiple perspectives presented helped students to recognize personal biases and shed light on the various perspectives through each student's individual lens. Since learning beyond the textbook and classroom entails understanding a variety of perspectives, it is necessary to give students the opportunities to do so in collaborative ways. I have found that students, in turn, appreciate learning from their peers, gathering new information and constructing purposeful meaning. In a collaborative classroom, every student's contribution to the group is equally important. Therefore, it is important that students are not isolated but work together to enrich their learning and make sense of the world in new and interesting ways.

Overall, shared responsibility, shared knowledge, teacher as facilitator, and group diversity are all beneficial aspects of a collaborative classroom. They lead to interactions that are far different from those in a traditional classroom. In my experience, students working together results in a greater and much richer understanding of material compared to students working in isolation and independently.

\section{Barriers to collaborative learning in my classroom}

Classrooms are complex and it goes without question that all classrooms are made up of diverse learners with varying learning needs. While there are several benefits to collaborative learning, there are also certain barriers that need to be addressed. Some barriers to collaboration that I have seen include class size, class composition, curriculum demands, traditional school structure, differing learning styles, classroom environment, hierarchal school nature, lack of individual social skills, lack of student focus, and student behaviour issues. As a result, the pursuit of 
collaborative learning can be challenging. Of the many barriers I have experienced, I will focus on the most predominant barriers I encounter: the traditional school structure and the lack of student focus.

The traditional school structure may be one of the biggest barriers to collaborative learning in the classroom. The traditional classroom and grading structure seem to compliment a system that is based on teacher lecturing and student memorization, as tests are given to see what knowledge a student has assimilated. Some students seem to be so accustomed to this traditional structure that when prompted to do collaborative work, it is often difficult for them. The very existence of a grading system may set students up to being in competition with each other, and students may be less willing to work with others, in fear that they will lose their competitive edge. Of course, this is just one example that I have observed in my classroom. I have seen students being very preoccupied about getting good grades and obtaining the right answer that sometimes they withhold sharing ideas in a group setting that they perceive would be beneficial to others. Moreover, students may be so worried about obtaining the right answer that they may not communicate their ideas for fear of being wrong or for fear of what others will think. Sawyer characterises this as social inhibition, which is when a member of a group withholds an idea in fear of what others will think (Sawyer, 2007). I have observed that some of my students seem to become anxious if they perceive that I am 'watching' them, and they seem to worry about what I think rather than what their group members think. In order to lessen the negative effect of social inhibition, I strive to act as a facilitator and not as an authoritative figure during collaborative learning opportunities (Sawyer, 2007). For example, I explain to my students my role and through teacher modelling I provide students with examples of how I am going to proceed. With enough practice, students better understand my role as facilitator during collaborative learning. As students are in groups, I circulate around the classroom, guiding student inquiries, encouraging student problem-solving, probing student thinking and providing positive feedback and positive reinforcement.

Despite my efforts as a facilitator, the traditional role of the teacher as authority figure is still embedded in the minds of some students, which I view as another barrier to collaborative learning in my classroom. Students 
may be so accustomed seeing teachers as authority figures from their years of exposure in predominantly traditional classroom settings that they can have a difficult time believing that they can have a part in co-constructing their own learning. Nevertheless, there are steps that can be taken to help overcome the barriers that a traditional classroom presents. One way to overcome this barrier is introducing collaborative learning to students at a young age, as they may be more likely to become habituated to it, and find collaborative learning situations less of a challenge. A more facilitative role, rather than being a simple bearer of information as seen in a traditional classroom, can help students feel empowered, construct meaning and come to an understanding of important ideas.

Another major barrier to collaborative learning in my classroom is the lack of student focus during group work, which can cause students to be highly unproductive. Students may find it exciting to be working with their friends and working away from direct teacher supervision. Accordingly, they may have the tendency to get side-tracked and be unproductive during group work situations. This barrier to collaborative work is discussed by Sawyer in his book Group Genius: The Creative Power of Collaboration (2007). For instance, Sawyer mentions that members of a group might be distracted from sharing their own ideas "by the flurry of idea generation around them" (Sawyer, 2007, pg. 64). Based on my classroom observations, I am in agreement with Sawyer, as I have noticed that when students are in larger groups, it is much more challenging for students to participate and the overstimulation of ideas can cause students to lose focus and thus, become distracted from the collaborative learning session. Sawyer also puts forward the notion of social loafing, which is when members of a group do not feel as accountable as when working alone (Sawyer, 2007). This can be another reason as to why students are side-tracked and lack focus during collaborative work. For instance, some students seem to take advantage of being in groups and feel they do not need to work as much as when they are alone. This is why I feel it is important to establish criteria for working collaboratively in groups. As a result, students are more likely to stay on task.

In my classroom, I have found it beneficial to create class generated criteria for both group work and for the specified assignment, as well as 
having students self-assess and peer-assess one another. Accordingly, students take responsibility for their learning. Enabling students to engage in self and peer assessment offers several advantages. For instance, it encourages student involvement and responsibility, it promotes thoughtful and critical reflection, and it helps focus students' attention on the objectives. As a result, the collaboration is purposeful and meaningful. I feel that if students are exposed to collaborative work environments early in their educational journey with established criteria for working collaboratively, it will habituate them to collaborative learning experiences, and make them less likely to lose focus and better concentrate on the collaborative process.

It is important to note that while traditional teaching methods may present a barrier to collaborative teaching in a classroom, there are instances in which traditional approaches are required for foundational knowledge, such as learning the periodic table, the multiplication table, or phonics in reading. For instance, the product of $2 \times 2$ is 4 and is simply factual, regardless of being in a collaborative classroom or not. This foundational knowledge is useful when students are given other questions where the foundational base is key, such as solving mathematical word problems that require basic multiplication. Hence, a traditional approach is needed in some circumstances. In my experiences, basic foundational skills are essential prior to moving on to more complex problems within a subject area. In a collaborative classroom, the lecturing process need not disappear entirely, but can work alongside other processes that can make the classroom a collaborative community.

\section{Building a community of collaborative inquiry}

How does one establish a community of collaborative inquiry? Why is it important to facilitate robust collaborative learning opportunities? First, I will highlight that in order for students to be active collaborative participants, classroom environments have to be established in a way in which collaborative learning can be fostered as meaningful and purposeful. I feel it is important for educators using collaborative learning, to establish an environment and create a community that is continually nurtured, in which students feel safe and comfortable taking risks and sharing ideas. I am in 
agreement with Rogoff (1994) who suggests that there is a significant difference between classrooms as communities compared to student-run and teacher-run classrooms. Student-run classrooms refer to student-directed learning in which students initiate and decide for themselves what they would like to learn and the teacher responds to and permits students to construct their own understandings. The teacher does not intervene with student learning. This is in contrast to a traditional teacher-run classroom, in which the teacher makes all the decisions and creates the agenda for the class. Students in a traditional classroom are therefore passive learners (Case \& Baclean, 2008). In my opinion, both of these classroom types seem quite extreme and counterproductive to a collaborative classroom. "Studies suggest that traditional teacher-directed classes may not create an atmosphere conducive to student thoughtfulness" (Case \& Baclean, 2008, p. 89) so student-run and teacher-run classrooms do not support collaboration as do community classrooms. This is why I stress the importance of establishing a classroom-oriented community.

I present a 'classroom as community' as a positive classroom environment that fosters collaborative inquiry, as it requires collaborative decision making from both students and teachers. In a community classroom, decision-making is a shared responsibility. The students and the teacher mutually reach decisions through joint negotiation within certain parameters. I am in agreement with Case \& Baclean (2008) who maintain that as students intermingle, the teacher's role is that of a mentor or facilitator who teaches the tools necessary to help students attain purposeful responses to open ended tasks. Overall, in a classroom as community, learning and teaching are ultimately collaborative, in which "the teacher's role is to frame the tasks, actively mentor students, and support students in developing the tools they need in order to reach thoughtful conclusions" (Case \& Baclean, 2008 , p.93). It may seem as though a community classroom is quite idealistic, so how can one nurture this type of environment in the classroom in order to strengthen collaborative learning?

Based on the review of the literature on strategies for building community classrooms, five main factors come to the surface (Case \& Baclean, 2008). First, in order to build a classroom community of collaborative inquiry, students and teachers mutually set appropriate 
classroom expectations. In order to stimulate and enhance student thinking, one possible expectation could be that both students and teachers are expected to consider other viewpoints on a given query and alternative approaches to an issue before reaching a justified conclusion. Hence, the strengths and weaknesses of a given position should always be explored as well as the possible solutions. Second, the implementation of classroom activities and routines also helps promote a community of collaborative thinkers. Such activities and routines may include establishing criteria together based on the learning outcomes for assignments, allowing students sufficient time to reflect on their learning before asking them to share their thoughts, and seriously considering student suggestions and ideas when developing activities or establishing classroom rules. Third, teacher modelling is a helpful strategy to aid in developing a classroom as community. After all, if I want my students to be good collaborators, I must first model these attributes to demonstrate what I mean, such as good listening, fair evaluation of arguments, avoiding generalizations and being open-minded and willing to alter my position if new perspectives transform my thinking. Fourth, shaping communicative interactions to stimulate student thinking is an important factor for building a community of collaborative inquiry. Such interactions are characterized as peer interactions, whole class discussions, or teacher-student communication. In contrast, these interactions are not usually present in traditional classrooms. I have found that a combination of such interactions leads to a positive collaborative learning environment. Finally, success is not likely if the majority of students do not possess the necessary skills to contribute to the collaborative classroom community (Case \& Baclean, 2008). In my case, I have found that it is essential to teach students how to be respectful in a collaborative learning situation by co-creating criteria that is reflective of a safe, inclusive collaborative environment.

It is important to note that although these strategies are quite useful in establishing a community of collaborative inquiry, limitations to these strategies are also present. For instance, the notion of teacher dominance can be problematic and can be challenging to discard being in the constraints of a traditional system (Case \& Baclean, 2008). It is important that educators remind themselves that their role is that of a facilitator and collaborator, so if 
the intent is to establish a collaborative classroom community, educators need to recognize that most of the communicative interaction should come from the students (Case \& Baclean, 2008). Overall, I contend that in order to build a thoughtful community of collaborative inquiry, educators need to set appropriate classroom expectations, implement classroom activities and routines, display teacher modelling, shape the communicative interactions to enhance thinking, and develop the necessary tools that students need in order to participate in the collaborative community.

\section{Conclusion}

Based on my observations, collaborative learning embodies several benefits, such as student empowerment and shared knowledge. How can educators bridge away from the traditional approach to one that is more appropriate to $21^{\text {st }}$ century learning? In order to facilitate collaborative inquiry, educators must shift away from the traditional classroom to one that encourages more collaborative-critical reflection and active participation. Thus, establishing the classroom environment by building a community is a helpful way to create opportunities for students to work collaboratively. As a result, students are able to work through problems together, clarify ideas, and evaluate multiple perspectives before reaching a consensus. I assert that collaboration is the first step in the process of independent critical thinking. Altogether, there is a great potential for collaborative learning to be a powerful learning tool in the classroom to achieve collaborative inquiry. However, challenges, such as the traditional classroom structure, continue to exist which may impede with its overall effectiveness. These factors need to be taken into account and overcome in order for collaborative learning to flourish at its full potential.

Future research needs to investigate the effect of different variables in collaborative learning situations, such as group composition, cultural dimensions, group selection and varying learning styles. Also, research on overcoming barriers in an elementary school classroom needs to be investigated and closely examined, as well as methods used to facilitate collaborative learning opportunities. Finally, future exploration on the interplay between critical and creative thinking in a collaborative classroom 
community environment would serve to enrich the subject area. In my case, I will continue to put collaborative learning into practice. The incorporation of collaborative learning in the classroom will help equip students to work and succeed in our increasingly inter-connected world.

\section{References}

Bruner, J. (1985). Vygotsky: An historical and conceptual perspective. Culture, communication, and cognition: Vygotskian perspectives. (pp 21-34). London: Cambridge University Press.

Cannon, R., Ingleton, C., Kiley, M., \& Rogers, T. (2000). Leap into Student Centred Learning. The University of Adelaide.

Case, R. (2005). Bringing critical thinking to the main stage, Education Canada, 45(2), 45-49.

Case, R \& Baclean, P (2008). Supporting a community of critical thinkers. In R. Case \& P. Clark. (Eds.) The anthology of social studies: Issues and strategies for Elementary teachers, Volume 1, pp. 89-98. Vancouver: Pacific Educational Press.

Cornelius-White, J. (2007). Learner-centred teacher-student relationships are effective: A meta-analysis. Review of Educational Research, 77(1), pp 113-143.

Dewey, J. (1930). Democracy and Education: An introduction to the philosophy of education.

Hennessy, D. (2006). Small-group learning in the community college classroom, 12(1). Community College enterprise.

Johnston-Parsons, M., (2010). Dreaming of Collaboration. Language Arts, 87(4), pp 287295, National council of teachers of English.

Rogoff, B. (1994) Developing Understanding of the idea of Communities of Learners. Mind, Culture, and Activity, 1(4), pp 209-229.

Sawyer, K., (2007) Group Genius: The Creative Power of Collaboration (Chapter 4) pp. 59-74 Sullivan, A.M. (2002) Pursuit of goals in partnerships: Empowerment in practice. Brisbane, Australia, Curtin University of technology.

Vygotsky, L. (1978). Mind in Society: The Development of Higher Psychological Processes. Cambridge: Harvard University Press 